\title{
Soldados de la patria. Motines y representaciones militares en Chile (1825-1827)
}

\author{
Valentina Verbal Stockmeyer ${ }^{1}$ \\ Recibido: 20 de marzo de 2016 - Aceptado: 15 de abril de 2016
}

\begin{abstract}
Resumen
Este artículo apunta a explicar el significado político de algunos motines y representaciones militares de carácter gremial, acontecidos en Chile durante el período 1823-1830, conocido como de anarquía o aprendizaje, según la interpretación historiográfica de que se trate. En términos generales, busca acercarse a la cuestión del militarismo en la formación de la República, fenómeno poco estudiado, negado o minimizado por gran parte de la historiografía tradicional y reciente.
\end{abstract}

Palabras clave: Período 1823-1830, militarismo, motines militares, representaciones militares.

\section{Soldiers of the homeland. Riots and military representations in Chile (1825-1827)}

\begin{abstract}
This article aims to explain the political significance of some riots and military representations with characteristics of a labor union, occurred in Chile during the 1823-1830 period, known as anarchy or learning, according to the historiographical interpretation applied. Generally speaking, it seeks to approach the question of militarism in the formation of the Republic, a phenomenon little studied, denied or downplayed by much of the traditional and recent historiography.
\end{abstract}

Keywords: 1823-1830 period, militarism, military riots, military representations.

\footnotetext{
Chilena. Magíster en Historia, Universidad de Chile. Profesora del Departamento de Formación General de la Universidad Viña del Mar, Chile. E-mail: valeverbal@gmail.com

Este artículo forma parte de la tesis de Magíster titulada "Soldados de la Patria. Militarismo e insubordinación militar en la formación de la República en Chile (1823-1828)", Santiago, Universidad de Chile, Facultad de Filosofía y Humanidades, Departamento de Ciencias Históricas, 2015. Agradezco los comentarios de Cristián Guerrero Lira, profesor guía, así como de Gabriel Salazar Vergara y Leonardo León Solís, profesores informantes.
} 


\title{
Soldados da pátria. Tumultos e representações militares no chile (1825-1827)
}

\begin{abstract}
Resumo
Este artigo tem como objetivo explicar o significado político de alguns tumultos e representações militares de caráter gremial, acontecidos no Chile durante 0 período de 1823-1830, conhecido como anarquia ou aprendizagem, segundo a interpretação historiográfica em questão. De modo geral, procura abordar a questão do militarismo na formação da República, fenômeno pouco estudado, negado ou minimizado por grande parte da historiografia tradicional e recente.
\end{abstract}

Palavras-chave: Período 1823-1830, militarismo, motins militares, representações militares.

Sin lugar a dudas, el período 1823-1830 -tipificado por algunos historiadores como de anarquía, y por otros como de aprendizaje ${ }^{2}-$, ha sido mucho menos estudiado que el anterior, representado por el Gobierno de O'Higgins (1817-1823), y que el posterior, normalmente encarnado en la figura de Diego Portales (1830-1837). ${ }^{3}$ Por ejemplo, la última edición del epistolario de Portales contiene un listado actualizado de las obras que sobre él se han escrito, alcanzando la cantidad de ciento dos (Fariña, 2007: 707711). ${ }^{4}$ En cambio, el número de trabajos sobre Ramón Freire es ínfimo, casi no pasando de biografías breves que lo destacan básicamente como militar, pero entrando muy de pasada en el campo de su actuación política. ${ }^{5}$ Tiene razón Simon Collier cuando afirma que "Freire sigue en espera de un buen biógrafo" (1977: 201).

Asimismo, el período en cuestión ha sido tratado en mucha menor medida desde la perspectiva de las relaciones civiles-militares, en particular del militarismo existente en esos años. La mayoría de los autores no ha abordado con profundidad este fenómeno. Diego Barros Arana, si bien le asigna gran importancia al papel de los militares en la época, entiende el militarismo ${ }^{6}$ como una consecuencia natural del clima general de desgobierno y desorden

2 Para la primera de estas visiones, una obra canónica es Alberto Edwards (1928). Para la segunda, Julio Heise (1978).

3 Aunque Portales ya comenzó a destacarse como político en la segunda mitad de la década de 1820, fue a partir de la siguiente en que adquirió un mayor relieve, puesto que ejerció el cargo de Ministro de Estado en dos ocasiones (1830-1831 y 1835-1837).

4 A esto habría que añadir la gran cantidad de obras generales sobre el período autoritario o conservador (1831-1861).

5 Sobre este personaje pueden revisarse Barros Arana (1852), Reyno (1952), Alemparte (1963). Obviamente, la figura de Freire ha sido parte de diversas obras de conjunto sobre la Independencia y la formación de la República en Chile. Recientemente, Salazar (2006).

6 Hay que aclarar que no utiliza este término, puesto que, aunque surgió en Francia en 1851, al parecer no era de uso general en Chile a fines del siglo XIX. Para el origen del concepto en Europa, ver Rodrigo Borja, 
reinante en Chile ${ }^{7}$. Alberto Edwards, aunque reconoce el prestigio que los militares habían adquirido en los campos de batalla, se limita a plantear un principio de carácter normativo: "El ejército, por su naturaleza misma, no era capaz de proporcionar al país un gobierno serio, estable e ilustrado, ni menos de concebir una organización definitiva y adaptada a la índole y a las necesidades del país" (1949: 21).

No obstante que la historiografía reciente ha abordado el tema con algo más de detalle, tiende a negar o minimizar el fenómeno militarista para los años de formación de la República. Un caso claro de negación es el de Julio Heise González, quien afirma: "La etapa de organización del Estado no conoció en Chile el militarismo. Los soldados que actúan en esta época -O'Higgins y Freire- fueron exaltados por elementos civiles, como símbolos de gloria y orgullo nacional y ellos se inclinaron ante el poder civil y ante la juridicidad" (1978: 128).

Un caso, por su parte, de minimización es el de Sergio Vergara Quiroz: "Desde 1823, con la caída del Gobierno de O'Higgins, y hasta 1837, por un espacio de 14 años, tendremos el 'militarismo' como un peligro eventual, expresándose en conspiraciones y motines" (1993: 99). Y agrega: "En definitiva, entre 1823 y 1837, se vivió en Chile un 'militarismo latente'. El Ejército, por una parte, no es tan fuerte como para imponer sus hombres, sus propósitos y, por otra, la elite santiaguina, aunque no participa del poder, no logra controlar la disciplina y subordinación del cuerpo militar" (1993: 99-100).

Estas visiones tienen en común el reducir el concepto de militarismo a la existencia de regímenes militares, o gobiernos militares de carácter corporativo. ${ }^{8}$ En otras palabras, se tiende a confundir el concepto de militarismo con el de pretorianismo, que es la forma más extrema del primero y que tiene como

"Militarismo", Enciclopedia de la Política. Internet: http://www.enciclopediadelapolitica.org/Default.aspx?i=

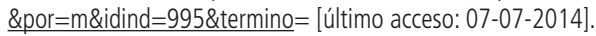

7 Al referirse a diversas acciones de insubordinación militar, producidas en la provincia de Colchagua, durante los primeros meses de 1828, señala: "Si estos disturbios pudieron ser fácilmente reprimidos, y si por entonces no tuvieron consecuencias más dolorosas, era evidente que ellos no eran, como creían muchos, el fruto aislado de pequeñas circunstancias locales, sino el resultado natural de la desorganización de la República, creciente desde 1823. La repetición cada día más frecuente de estos movimientos, venía anunciando la proximidad de una era de espantosa anarquía, y los que se forjaban la ilusión de una pronta y feliz represión de cada uno de ellos, así como el contento público con que eran recibidos el desenlace conciliatorio y el indulto de los facciosos, eran signos de bonanza y de paz, sufrían un engaño que los acontecimientos subsiguientes vinieron a demostrar". Barros Arana (2005b: 173-174).

8 Considerando que se trata de un concepto ambiguo, distinguimos dos tipos de militarismo: a) amplio: prominencia de los militares en la vida política, que puede o no incluir su participación en gobiernos y parlamentos; y b) estricto: intervención política de los militares a partir del uso ilegítimo de la fuerza estatal. Ambos, a su vez, suelen producirse con mayor facilidad en un contexto de militarismo social o cultural. Para esta visión amplia, puede revisarse Oehling (1977) y Pasquino (2007: 962-970). 
resultado final la total anulación de las elites civiles como actores políticos, situación que no aconteció en el período 1823-1830.9

De hecho, las insubordinaciones políticas de la época -especialmente, las o'higginistas de 1825 y 1826, y las con tinte federalista de 1827 y $1828^{10}$ - demuestran que lo que hubo en Chile fue una actuación conjunta entre civiles y militares con fines partidistas, en el sentido de representar a sectores parciales de la política nacional de ese entonces. Siguiendo a Samuel E. Finer, puede hablarse de la existencia de una política dual o civil-militar antes que la subordinación absoluta de uno de estos estamentos por sobre el otro (1969: 117).

El objetivo de este trabajo es revisar algunas acciones de insubordinación castrense de carácter económico, esto es, que tenían como propósito fundamental obtener, de parte de las autoridades políticas (gobiernos y parlamentos), el pago de los sueldos atrasados a la tropa. Además, y en el contexto de algunas representaciones de oficiales al Congreso en 1825, se buscará escudriñar en la imagen que los militares tenían de sí mismos y de las elites civiles a las que debían ellos subordinarse. De esta manera, se aportará una explicación sobre el significado político del militarismo gremial del período de formación de la República.

Como información previa, cabe consignar que -conforme a un decreto del Ministro de Guerra, Francisco Antonio Pinto, de fecha 14 de octubre de 1824- los soldados ganaban en la época asociada a este trabajo 7 pesos, y los cabos y sargentos entre 9 y 15 pesos mensuales (Varas, 1870: 182-185). Las diferencias emanaban del grado y especialidad. Por ejemplo, el personal de artillería -por su carácter más técnico- recibía un sueldo mayor al de infantería y caballería.

Considerando estas cifras, ¿a cuánto ascendían los sueldos de los trabajadores del mundo civil? Un estudio del Instituto de Economía de la Pontificia Universidad Católica de Chile establece que en los años aquí estudiados el promedio de los salarios reales giraba en torno a los 5-6 pesos (Varios autores, 2000: 174). En este sentido, puede afirmarse que los sueldos de los soldados eran en promedio mejores que los del mundo civil.

Gabriel Salazar no es de la misma idea: "El peonaje militar comenzó a recibir un prest (salario) considerablemente inferior al del peón libre. De hecho, el prest del Ejército bajó un 30 por ciento con respecto al de sus ni-

9 Samuel P. Huntington describe la sociedad pretoriana como aquella situación en que "no se reconocen ni se aceptan instituciones políticas, ni cuerpos de dirigentes políticos profesionales, como intermediarios legítimos para moderar los conflictos entre grupos" (1972: 178).

10 Además de las de 1823 y 1829, ambas lideradas por el Ejército del Sur, aunque por bandos contrarios. 
veles del período colonial". Y añade que el costo en alimentación (rancho) era prácticamente equivalente al nivel de los salarios (2000: 245). Este autor considera la cifra de 6 pesos a partir de un documento de la guarnición de Concepción que, precisamente, para solicitar los pagos adeudados, refiere únicamente el sueldo más bajo, correspondiente a los soldados en sentido estricto, pero sin considerar los grados sucesivos, como los de cabo y sargento, que se encontraban en la misma situación de acreencia. ${ }^{11}$

Sergio Vergara sostiene que en "los años del proceso emancipador se observa un moderado incremento de un $20 \%$ aproximado, especialmente para la caballería y los grados de capitán a coronel. Los sueldos de los grados más bajos y numerosos, como los de subteniente y teniente, crecieron menos, permaneciendo iguales a los de los soldados" (1993: 103). Pero más allá de esto, y como este mismo autor lo subraya, el problema era que -en la práctica, y en buena medida producto de la pésima situación económica existente ${ }^{12}$ - los sueldos no solían ser cancelados; o, al menos, no de manera oportuna.

Por último, es importante recordar que el ejército de la época se encontraba habitualmente abocado a combatir la violencia social que asumía distintas tipologías, como el bandolerismo y la montonera. ${ }^{13}$ Esta situación, siguiendo a Lorenzo Cotino Hueso, constituye, a nivel comparado, uno de los principales factores de intervencionismo militar (2007: 35). ${ }^{14}$

11 El documento citado por Salazar es Fondo Intendencia de Concepción, Volumen 86 (1826), s/f (Archivo Nacional Histórico).

12 Célebre sigue siendo hoy la memoria presentada al Senado en 1824 por Diego José Benavente, Ministro de Hacienda: "El Senado debe estar persuadido que la hacienda de la República es enteramente nula, y también debe estarlo que sin hacienda no hay independencia, no hay libertad, no hay leyes, nada hay" (Benavente, 2010: 117).

13 Ivette Lozoya distingue entre delincuente, bandolero y montonero. El primero es "el delincuente ocasional, el que transgrede, violenta a través del robo, pero no adopta esa conducta sólo como forma de subsistencia, sino como parte de su identidad desarraigada". El segundo, el delincuente que asume la violencia como forma de subsistencia. Y el tercero, el guerrillero que persigue fines directamente políticos (Lozoya, 2014: 38). Un caso, que Ana María Contador tipifica como banda guerrillera, es el de los hermanos Pincheira (1998).

14 Este autor enumera y describe dieciséis factores de intervención militar, pero pensando en nuestro tema destaquemos los siguientes cinco: a) la falta de suficiente legitimidad del poder civil, lo que hace que los militares Ilenen el vacío de poder existente; b) la escasa cultura democrática, por ejemplo, la poca valoración del pluralismo ideológico y de la búsqueda de acuerdos; c) la menor complejidad del sistema institucional, ya que, al existir una escasa diferenciación funcional, los civiles tienden a ser más proclives a la participación política de los militares y éstos se sienten llamados a intervenir; d) la mayor implicación de las fuerzas armadas en misiones de orden público, lo que las aleja de su misión esencial, que es prepararse para la guerra exterior; y e) el grado de profesionalidad: a menor profesionalidad, mayor es la potencialidad de la intervención militar. 


\section{Motines en Los Guindos y Yumbel, enero de 1825}

Siendo Los Guindos una pequeña localidad cercana a la ciudad de Chillán, el 2 de enero de 1825 se produjo un motín de soldados en contra de oficiales. Los amotinados aprovecharon la circunstancia que su comandante, Manuel Bulnes, se encontraba, desde diciembre pasado, en persecución de la banda de los hermanos Pincheira. Luego de apresar a los oficiales, se dirigieron a San Carlos. Diego Barros Arana narra estos hechos como sigue:

"Aprisionado el Gobernador local, e incorporada a los asaltantes una compañía incompleta de infantería de línea que estaba allí de guarnición, el vecindario fue saqueado despiadadamente durante algunas horas, al cabo de las cuales los Cazadores sublevados tomaron el camino de la montaña, llevando a la grupa de sus caballos a los infantes que se habían plegado a la rebelión, y dejando dicho que irían a juntarse a los Pincheira si en un breve plazo no se les entregaban cinco mil pesos a cuenta de sus sueldos atrasados" (2005a: 315).

La información precedente fue confirmada dos días después por el Intendente de Concepción, Juan de Dios Rivera:

"Los Cazadores han arrasado [con] la guarnición de infantería, compuesta de 40 hombres y 30 dragones, existente en San Carlos. Se sabe que ya se disponían para pasar sobre Parral y probablemente van a hacer cooperantes de tan horrendo crimen al resto de las tropas que cubrían el cantón de cordillera. Mucho paisano se les ha reunido a los Pincheira, que días antes salió con cerca de 400 hombres. Le han mandado avisos para su pronta venida. Si este mal ejemplo se hiciese trascendental en el Ejército, en este caso la provincia [será] víctima de la ferocidad desenfrenada. ${ }^{15 "}$

El 10 de enero, el Gobierno informó al Congreso de "un suceso desagradable acaecido en la provincia de Concepción" (Letelier, 1901a: 244). El diputado Domingo Torres hizo ver la gravedad del asunto, señalando que "la falta de pago ha sido el motivo que alegan los amotinados por haber dado un paso tan escandaloso y de funesta trascendencia, que acaso a estas horas en los demás cuerpos de aquel ejército (no obstante su disciplina) se hayan sentido iguales efectos, todo originado por el mismo principio". Y en favor de los soldados, agregó:

15 Fondo Intendencia de Concepción, Tomo 62, foja 44 (Archivo Nacional Histórico). Este documento (y de manera más legible) también puede verse en el Fondo Ministerio de Guerra, Tomo 146, foja s/n (Archivo Nacional Histórico). 
"Yo desearía que los hombres más imparciales observasen de cerca el mérito de los soldados del Ejército del Sur; pues estoy convencido que confesarían francamente que no son soldados de la Patria, sino esclavos de ella. Sí, esclavos, porque a ellos se les exige toda clase de sacrificios y privaciones, al paso que se les hace sentir todo el peso de la escasez del erario público. Se me dirá, y con razón, que el ejecutivo ha estado trabado por la Constitución de 1823 para adquirir recursos y consiguientemente no auxiliar oportunamente a las tropas. Yo contestaré que es muy cierto, al paso que lo es también una especie de espíritu de ingratitud nacional que mira con la mayor indiferencia el bienestar del Ejército, de esos hombres que han salvado la República en los grandes conflictos, y que a ellos exclusivamente se debe la libertad que gozan hoy día los ciudadanos de Chile" (Letelier, 1901a: 243).

El segundo motín tuvo lugar en Yumbel, unos pocos días después, el 16 de enero. Mientras que Manuel Jordán ${ }^{16}$, comandante de las tropas acantonadas en este pueblo, se había trasladado con algunos soldados a sofocar la sedición de Los Guindos, las demás se amotinaron, exigiendo también el pago de sus sueldos atrasados. Según Barros Arana, esta insubordinación pudo ser reprimida gracias a un piquete de artilleros con dos cañones que, incluso, dio muerte a "dos soldados que parecían encabezar el motín, y mediante una capitulación de los demás insurrectos" (2005a: 315).

Al día siguiente de acontecido, el Intendente Juan de Dios Rivera se refirió con preocupación a este suceso 17: "La sedición del escuadrón de Cazadores a caballo ha influido notablemente en el Ejército. Un movimiento que se creyó parcial, se iba haciendo general. Las muestras se divisaron el 12 y 16 del corriente en la plaza de Yumbel, y en Concepción se sintió la noche del 13 ". Y antes de aclarar que su causa era "la falta de pagas", agregó:

"Como la impunidad de los grandes crímenes es el medio seguro de multiplicarlos, he resuelto que el piquete de cincuenta y tantos hombres del batallón $N^{0} 11$, que reiteró en Yumbel la sublevación, sea pasado por las armas a la vista del ejército, de todos los que se encuentren en esta operación. Esta providencia [...] la creo de urgentísima necesidad y que en iguales circunstancias se ha adoptado para aquietar las rebeliones. Vienen marchando hacia este punto y la ejecución no tardará más tiempo que el preciso." 18

Como biografía breve de este personaje, ver González (1963: 66-68).

A través de un oficio dirigido al Ministro de Guerra.

Fondo Intendencia de Concepción, Tomo 62, foja 45 (Archivo Nacional Histórico). También se puede ver en el Fondo Ministerio de Guerra, Tomo 146, foja s/n (Archivo Nacional Histórico). 
Estos motines generaron importantes debates parlamentarios en torno a la búsqueda de una solución para cancelar los sueldos adeudados. ${ }^{19}$ En la sesión del 10 de enero -el mismo día cuando los parlamentarios se enteraron del motín de Los Guindos- se aprobó en el Congreso una propuesta del Gobierno referida a la contratación de un empréstito destinado a cubrir de manera suficiente los sueldos de la tropa. El diputado José Gregorio de Argomedo señaló que esta medida debía considerarse como último recurso: "Parece muy bien este medio, añadiendo sólo la palabra que el ejecutivo levante el empréstito si no encontrase otro arbitrio ${ }^{20}$. Yo creo que con esta adición están conciliadas todas las opiniones, porque lo que se pide es para pagar la tropa y debemos tener presente que a todas las tropas se les debe y no hacemos más que adelantar, que si hubiese otro medio menos malo se adopte" (Letelier, 1901a: 243).

\section{Insubordinaciones en Santiago, septiembre y octubre de 1826}

El 20 de septiembre de 1826 -en la misma sesión parlamentaria en que se discutía en torno a un proyecto sobre ejército permanente- los diputados se enteraron que los tres batallones de infantería de Santiago se habían amotinado, exigiendo que, en un plazo de cuatro días, les fuesen pagados sus sueldos atrasados (Barros Arana, 2005b: 77). En este caso, se trató de una acción encabezada por oficiales.

Aunque el documento presentado al Congreso por los oficiales de las mencionadas unidades subrayaba que su representación se hacía "con todo el orden posible" y "con anuencia de los jefes de los cuerpos", los diputados no dudaron en calificar el hecho como "un escandaloso movimiento militar" y como una "insurrección" (Letelier, 1901c: 90).

De esta manera, el Congreso le preguntó al Vicepresidente Agustín de Eyzaguirre ${ }^{21}$ sobre las personas "que se hallan a su cabeza, si los jefes la han apoyado ya directa o indirectamente, y [sobre el] objeto que ella puede tener por los antecedentes de que no debe carecer el Supremo Poder Ejecutivo" (Letelier, 1901c: 90). Además, encomendó a los diputados José María Novoa

19 Un tercer motín que, por motivos de espacio no detallaremos en este artículo, se produjo en Chillán el 15 de junio de 1826. Esa noche, el sargento mayor Bernardino Escribano, segundo jefe de un escuadrón de caballería, se insubordinó en contra de su comandante, Domingo Torres, "apresándolo sorpresivamente y enviándolos con buena escolta a Concepción, a pretexto de que no pagaba los sueldos a la tropa" (Barros Arana, 2005a: 77).

20 Las cursivas aparecen en el acta de la sesión.

21 Quien gobernaba con carácter provisional frente a la renuncia de Manuel Blanco Encalada del 9 de septiembre de 1826. 
y Enrique Campino para que, junto al Gobierno, acordasen los medios para restablecer el orden público. Pero luego se supo que no existía realmente una insubordinación armada, sino simplemente una reclamación por los sueldos atrasados (Concha y Toro, 1862: 115).

La respuesta de Eyzaguirre fue categórica en cuanto a "que los jefes no han tenido intervención en él; que los cuarteles se hallan en tranquilidad, sin asomos por ahora de sublevación, y que-conforme al parte del Comandante General de Armas- no existe otro espíritu en la oficialidad que el que contiene una representación o acuerdo de aquella que el Jefe de las armas debe haber sometido ya a la Sala del Congreso" (Letelier, 1901c: 93).

En la sesión del día 22, el diputado Ignacio Molina presentó un proyecto de ley, cuyo artículo primero dispuso que: "No podrá ser jefe, con mando de fuerza, individuo alguno que no sea hijo del país" (Letelier, 1901c: 98). Esta moción tomaba en consideración que tres de los cuatro cuerpos militares de Santiago, estaban comandados por extranjeros (Barros Arana, 2005b: 77): Jorge Beauchef (francés), Jorge Rondizzoni (italiano) y Guillermo de Vic Tupper (británico). ${ }^{22}$

Sin embargo, dicha moción fue rechazada el mismo día. En buena medida, porque a la luz del informe presentado por el Gobierno, resultaba claro que dichos comandantes no habían tenido participación alguna en los hechos en cuestión. Por ejemplo, dicho informe consigna que Tupper se encontraba en su casa cuando una comisión de oficiales del batallón $N^{\circ} 8$, bajo su mando, se le presentó manifestándole el motivo de la acción por ellos encabezada. En todo caso, el 21 de septiembre el Gobierno informaba sobre su decisión de suspender provisoriamente a los comandantes Rondizzoni, Beauchef, Godoy y Tupper (Letelier, 1901c: 97).

Pese a que los documentos referidos sostienen que la acción del 20 de septiembre no constituyó un motín, por cuanto los insubordinados no se enfrentaron de manera armada en contra de sus comandantes, sí impidieron el acceso de ellos a los cuarteles mientras no representaran su demanda a las autoridades civiles.

Aunque se trata de una norma posterior a la época del presente estudio, conforme al artículo 272 del Código de Justicia Militar de Chile, promulgado en 1944, existe un motín cuando cuatro o más militares "rehúsen obedecer

22 Para los dos primeros y, en general, para los militares de influencia napoleónica en el Chile de la época, fundamental es el trabajo de Patrick Puigmal (2013). Esta obra, además de biografías breves, contiene una introducción general y un interesante análisis de la presencia de estos militares en los países que se indican. Un trabajo más breve, pero también de mérito, es el de Douglas Barry Wilkins y Patricio Vergara Undurraga (2013: 87-131). Una tercera obra, más reciente, es la de Fernando Berguño Hurtado (2015). 
a sus superiores, hagan reclamaciones o peticiones irrespetuosas o en tumulto, o se resistan a cumplir con sus deberes militares". Como se observa, técnicamente el concepto de motín es mucho más amplio que el referido en las fuentes de la época estudiada.

Por su parte, la Ordenanza General del Ejército de $1839^{23}$ (que es temporalmente cercana al evento en cuestión), a través de su artículo 1320, estableció el delito de sedición en los siguiente términos: "Los que emprendieren cualquiera sedición, conspiración o motín, indujeren a cometer estos delitos contra el servicio, seguridad de la plaza, contra la tropa, su comandante u oficiales, serán pasados por las armas en cualquier número que sean, y los que hubieren tenido noticia y no la delataren luego que puedan, sufrirán la misma pena" (Lara, 1923: 294)24. Los artículos siguientes establecen otras especies de este mismo delito, que incluyen, por ejemplo, la inducción, el grito tumultuario, etc., todos los cuales atentan contra el principio de jerarquía de manera amplia.

El punto a subrayar es que, no obstante que las fuentes señalen que no hubo motín propiamente tal, por no existir un uso directo de la fuerza, en un sentido amplio se trató de una insubordinación que, teórica y jurídicamente, sí puede ser calificada como tal.

Ahora bien, pensando en las modalidades de intervencionismo político, la acción aquí comentada puede tipificarse como una presión. Es decir, siguiendo a Samuel E. Finer, como una intimidación que lleva consigo una amenaza implícita, la que puede ser o no ser constitucional (1969: 116). Melchor de Concha y Toro, aunque obviamente no recoge esta tipología (que es posterior a él en un siglo), es, en el fondo, de la misma idea al sostener "que la tropa, pereciendo de hambre, tomó una actitud amenazante, tolerada por los comandantes que palpaban la justicia de las quejas" (1862: 116).

Exactamente un mes después de producida la acción anterior, en la madrugada del 20 de octubre, se amotinó el escuadrón de Guías ${ }^{25}$, liderado por el capitán José María Valenzuela, y que cumplía la función de servir de guardia del palacio de Gobierno (Barros Arana, 2005b: 78). Como Valenzuela no logró que los otros cuerpos siguieran sus pasos, optó por salir de Santiago y situarse en la villa de San Bernardo, a la espera de que la autoridad gubernativa aceptase pagar los sueldos atrasados. Concha y Toro dice que se dirigió a la chacra de Ochagavía y de ahí a Maipo (1862: 116). Francisco

23 Estos artículos se diferencian por el grado de los autores y por algunas circunstancias particulares de la tipificación.

24 Como se dijo en el cuerpo de este trabajo, esta ley fue promulgada por vez primera en 1839. La edición de 1923 aquí referida contiene todas las disposiciones anteriores, modificadas o derogadas.

25 Que era el cuerpo de caballería. 
Borcoski, comandante de esta unidad, "se presentó allí para someterla a la obediencia", [pero] fue recibido a balazos, y se vio forzado a regresar a Santiago, convencido de que sería necesario empeñar un ataque formal" (Barros Arana, 2005b: 78).

Pese a que las tropas de Valenzuela ascendían a 140 soldados, las autoridades temieron su traslado al sur, uniéndose a la banda de los Pincheira. Además, y debido a la ausencia de caballos que hiciesen frente a los Guías, el Gobierno optó por negociar, ofreciendo el pago de los sueldos atrasados a cambio de su regreso a la capital. Pero "Valenzuela, dudando de la sinceridad de esas proposiciones, exigía que la tropa fuera pagada en aquel campamento" (Barros Arana, 2005b: 78).

Finalmente, el asunto se resolvió gracias a la intervención directa del general Ramón Freire, quien gozaba de gran prestigio entre la tropa, como lo subraya Concha y Toro (1862: 116-117). El 6 de noviembre siguiente y tomando en cuenta este motín, un grupo de diputados presentó un proyecto de ley, cuyo artículo primero declaraba "traidores a la Patria los autores de las revoluciones contra el Gobierno y los que esparcen noticias subversivas del orden" (Letelier, 1901c: 247)26. Pero, en la misma sesión de ese día, dicha moción fue pasada a la Comisión de Justicia, no siendo, al parecer, discutida ni menos aún aprobada (Letelier, 1901c: 246).

\section{El Motín en Talca, 21 de julio de $1827^{27}$}

Uno de los graves problemas en la aplicación del régimen federal, fue el de demarcación territorial. En el caso de Talca esto supuso la creación de una Junta llamada Comisión representativa, que se negó tajantemente a someterse a la asamblea que funcionaba en Curicó. Pese a este contexto, Barros Arana recalca que las tropas -que en su mayor parte regresaban desde el sur de su campaña en contra de los Pincheira- "eran completamente extrañas a estas perturbaciones políticas, y nada hacía temer acto alguno de insurrección" (2005b: 136).

En ese momento, Talca estaba resguardada por un escuadrón de Cazadores a caballo que mandaba el teniente coronel Manuel Urquizo, y por el batallón № 1 (Chacabuco), a la sazón a cargo del sargento Manuel Navarro. ¿Qué sucedió? La noche del 21 de julio, a las tres de la madrugada, los soldados del escuadrón de Cazadores, liderados por algunos sargentos y cabos, se amotinaron en el convento de San Agustín, que hacía las veces de cuartel

Esta moción demuestra que, en la época, no existían normas precisas en materia de delitos castrenses.

A esta acción de insubordinación nos hemos referido con mayor extensión en Verbal (2012: 9-19). 
militar. Asimismo, "apresaron a los oficiales que dormían en él; se apoderaron de la guardia de la cárcel y del depósito de armas que allí había, y tomaron, además, como prisioneros a otros oficiales que vivían en la ciudad" (Barros Arana, 2005b: 136).

A la luz de las fuentes consultadas, resulta claro que este motín tuvo como causa inmediata el atraso en el pago de los sueldos de la tropa. El parte del comandante Urquizo del mismo día 21 -que podemos calificar como breve e inmediato- consigna que a "las nueve de la mañana se me hizo llamar por los sublevados, y lo verifiqué en el acto; en la entrevista me hicieron saber que únicamente reclamaban sus pagos, a lo que contesté: que no estaba en mis alcances el condescender con su petición, y aunque para contenerlos apuré todos los medios que en iguales casos dicta la prudencia, me fue enteramente imposible y el desorden tomaba ya un aspecto de gravedad" (Letelier, 1901d: 29).28

Citemos ahora, para una mejor comprensión de este primer elemento, el parte del día 23 -que podemos calificar como largo y posterior- en el que Urquizo afirmó lo siguiente:

"Observé que el que comandaba era el cabo de la 1ª, Bernardo Pérez, pues al preguntarse por mí quién era el autor de aquel movimiento y con quién me debía entender, se me contestó por éste que con él. Salió al frente, y héchole por mí los cargos del buen trato, y la exacta asistencia en un todo, con cuanto más pudo sugerirme la prudencia y el tino con que debía conducirme en aquel caso a fin de retraerlos al orden, se me contestó que todo era muy cierto, pero que carecían absolutamente de sus pagos, que se hallaban debiendo en el pueblo; que no tenían lo necesario de sus vicios, y que precisamente antes de deponer las armas habían de ser completamente ajustados.

Se le reprodujo por mí que el Gobierno no podía hacer más que lo que hacía; que acababan de recibir un vestuario; que trescientos y más pesos se me habían suplido a crédito en el pueblo para socorrerles seis días antes; que se esperaba al oficial conductor de caudales por momentos, en que serían socorridos de un modo bastante: que un escuadrón, que jamás había dado que notar en este orden me era muy sensible lo verificase ahora, en un pueblo de quien había merecido las mayores consideraciones y mejor hospitalidad. Le hice infinitas otras reflexiones; pero tenaz en su capricho, unas me rebatía y otras me despreciaba.

28 Los partes de Urquizo aparecen transcritos en la sesión del 1 de agosto de 1827. 
Viendo su terquedad traté de entrar en pacto, y después de varios debates quedamos acordes en que si se les daba cuatro pesos a cada uno, cesarían de la empresa. Convine en ello y me fui al Ilustre Cabildo que se hallaba reunido, e igualmente a la Asamblea, para que ambos cuerpos meditasen de dónde debía salir este dinero" (Letelier, 1901d: 30).

Un segundo elemento de hecho importante es que, finalmente, el incidente se resolvió por la vía armada. Señaló Urquizo en su parte del día 21: "Acordé en Junta de Guerra lo que se debía hacer en esta materia, y se resolvió repelerlos con el batallón Chacabuco y las milicias que pude reunir: ellos hicieron resistencia en la guardia de la cárcel y en el cuartel con bastante obstinación. Al ver que me eran infructuosas todas las medidas de pacificación me determiné a rendirlos a fuego, como efectivamente se verificó. Me anticipo a avisar a $\mathrm{Ud}$. este resultado porque más de treinta sublevados se han dirigido a esa capital" (Letelier, 1901d29). En el parte del día 23, Urquizo dio cuenta con más detalles del enfrentamiento armado a que dio lugar la intransigencia de los amotinados:

"Efectivamente se acordó que sin perder momento, se repeliesen los sublevados con la fuerza del batallón Chacabuco y el cuerpo de nacionales que ya estaba reunido. Se dio parte a la Asamblea y Cabildo de la resolución antecedente, y estando ambos cuerpos conformes en la determinación por ser llegado el último caso, y que se habían ya tocado todos los medios que dicta la buena razón, puse en práctica el ataque dando al efecto las órdenes siguientes. Al bravo teniente Barraza lo estaqué con 20 hombres a forzar y tomarse a todo trance la guardia de la cárcel, por ser la más importante, pues se hallaban bajo su custodia los diez mil tiros y el armamento de nacionales. El batallón, en seguida de la vanguardia, marchó bajo mis órdenes a distancia de 50 pasos. La intrepidez del teniente Barraza hizo rendirse por la fuerza a la citada guardia a pesar de haberse sostenido con vivo fuego" (Letelier, 1901d: 29).

Esta acción de armas concluyó con la muerte del teniente Barraza y de tres soldados de Cazadores. Urquizo informó de la pérdida total de "veintiún hombres entre fugados y muertos" (Letelier, 1901d: 30), incluyendo a los amotinados. En todo caso, resulta claro que los cabecillas del motín -Bernardo Pérez, Pablo Arriagada, José María Reyes y Rosauro Muñoz-fueron fusilados al día siguiente, es decir, el 22 de julio de 1827. En suma, y coordinando este documento con el oficio del Gobernador de Talca, Juan Nepumoceno Cruz, es posible concluir que, a lo menos, murieron cuatro hombres por el lado del Gobierno y, a su vez, cuatro por el lado de los amotinados: los cabecillas fusilados. 
Este motín puede calificarse, nuevamente siguiendo a Finer, como de interés sectorial y de clase ${ }^{29}$, ya que, a partir de la exigencia del pago de sueldos, la insubordinación procede de soldados y suboficiales en contra de oficiales, aunque sin apuntar a un derrocamiento de las autoridades civiles. Distinto es el caso -que veremos en el apartado siguiente- basado en un interés sectorial de carácter corporativo, en el que, en favor de los soldados y de ellos mismos, intervienen los oficiales ante las autoridades civiles.

Por último, y como un elemento de fondo, el periódico El Verdadero Liberal de 31 de julio de 1827, no obstante que acogió la misma tesis económica de las fuentes arriba citadas, puso el acento en un clima político general de desorden, culpando al Gobierno del acontecimiento aquí referido: "En esta ocasión como en muchas otras hemos sido profetas, para lo cual no nos ha sido necesaria mucha perspicacia, sino solo un poco de buen sentido, y el conocimiento del estado actual del país. Ninguno habrá experimentado la menor sorpresa al saber lo acontecido en Talca, pues el árbol ha dado su fruto" (EI Verdadero Liberal, 31-VII-1827).

Esta nota, escrita por el francés Juan Chapuis, editor del periódico, fue fuertemente rechazada por el Gobierno. En efecto, y tal como da cuenta el periódico La Aurora del 8 de agosto de 1827:

"El $1^{\circ}$ del corriente fue encarcelado Mr. Chapuis, editor del Verdadero Liberal, de orden de su excelencia el Vicepresidente de la República, comunicada por escrito al juez de letras en lo criminal, por el artículo acontecimientos de Talca publicado en el núm. 60. El cargo de escribir para el público nos impone registrar este suceso en nuestras páginas para defender la ley de libertad de imprenta que se ha infringido por un golpe de autoridad. Confesamos que este artículo es descarado, indiscreto y ofensivo del respeto que se debe al Gobierno; pero teniendo éste un camino demarcado por las leyes para hacer vengar su ofensa, y castigar la licenciosa manera con que ese escritor se ha producido; cuando se le había presentado la oportunidad más favorable de ofrecer un escarmiento que enfrente la audacia de los que intentasen seguir su ejemplo pernicioso, es muy sensible que haya abusado del poder, invadiendo las fórmulas legales del juicio de imprenta, que constituyen las garantías más apreciables de las libertades públicas" (La Aurora, 8-VIII-1827).

29 Finer distingue tres grandes motivos de los militares para intervenir: a) el "destino manifiesto" de los militares: Supone el sentirse salvadores de la Patria; b) interés nacional: Se refiere al papel de custodios, sea como gobernantes o árbitros; c) interés sectorial: Es posible desglosarlo, a su vez, en tres tipos: i) interés de clase; ii) interés regional; y iii) interés corporativo (1969: 48-81). 


\section{Representaciones militares de 1825}

Durante los meses de abril y mayo de 1825, el Congreso tuvo que lidiar con diversas representaciones de los cuerpos militares de Santiago sobre la situación de la tropa y, en particular, referidas a la actitud ofensiva del diputado Carlos Rodríguez Erdoiza. Si bien estas representaciones no pueden calificarse como alzamientos o motines, se trata de acciones de intervención política, al menos en cuanto apuntaron a presionar a las autoridades civiles en torno a ciertas demandas de carácter gremial.

Además, en particular en el caso de la polémica con el diputado Rodríguez, de un claro conflicto entre las elites civiles y militares. Aquí podemos estar en presencia de la tipología de Finer como motivación de interés sectorial de carácter corporativo, ya que los oficiales actúan en defensa de la autonomía y de los derechos de todos sus miembros, incluyendo a soldados y suboficiales..$^{30}$

El 12 de abril de 1825, el Ministro del Interior, Francisco Ramón de Vicuña, a cargo provisionalmente del Ministerio de Guerra, le comunicó al Congreso que los cuerpos militares de la capita| ${ }^{31}$, al no tener cómo dar de comer a la tropa, habían decidido salir a los campos para procurarse el sustento. Y agregó que tal decisión contaba con la venia del Director Supremo, Ramón Freire (Letelier, 1901b: 130-131).

Es importante aclarar que esta representación se hizo por conducto regular. Los comandantes de los cuerpos se dirigieron al Comandante General de Armas, Luis de la Cruz, quien hizo lo propio con el Ministro de Guerra. Aunque el diputado Carlos Rodríguez consideró "conveniente y necesario se suspendiese al comandante general de su empleo hasta examinar los documentos que se habían ordenado traer a la vista" (Letelier, 1901b: 130), la sala votó mayoritariamente en contra de esta moción y a favor que dicho comandante trajese los oficios enviados al Ministro de Guerra, que daban cuenta de la decisión de marchar fuera de la capital.

El contexto del malestar planteado por los oficiales estuvo también representado por la lucha de los cuerpos militares contra de la banda de los hermanos Pincheira. De hecho, dos días después de la representación anteriormente referida, el Congreso se enteró de una comunicación del Comandante del Batallón $N^{\circ}$ 4, José Santiago Sanhueza, quien hizo presente la

30 Aunque Finer no define este interés en los mismos términos, pero sí considerando el mismo efecto. Más bien, él se refiere a la autonomía para decidir, por ejemplo, sobre asuntos técnicos que se consideran propios de la institución militar (1969: 66).

31 Se trataba de los batallones 5,7 y 8 , y el regimiento de Cazadores a caballo. 
gravedad de los desórdenes ocasionados por la banda referida y la necesidad de tomar medidas mucho más drásticas:

"El camino que media entre esta ciudad [Talca] y la de Rancagua está infestado de salteadores, y es raro el día que no se dice de asesinatos y robos cometidos por los malvados. Las correrías de Pincheira y su aproximación a estos partidos alarma a los mal intencionados, y fomenta partidas de ladrones. A cada paso se encuentra en los caminos hombres armados, y en muchas ocasiones reunidos de cuatro hasta doce que ponen en conflicto a los transeúntes y habitantes del campo. Bien sé que está en mis facultades perseguirlos y limpiar el camino de esta clase de gente; pero deseo saber qué destino se les da a los que se aprehendan, dónde se depositan, y con qué se mantienen; pues las cárceles son nada seguras y los pueblos no tienen fondos para sustentar los presos. Por otro lado, las causas generalmente son formadas con lentitud y los delitos al fin quedan impunes en la mayoría. Yo creo que, en las circunstancias en que se hallan estas delegaciones, convendría al bien público que todo salteador fuese ejecutado al momento, sin trámites legales, ni fórmulas forenses; pues a no hacerse así no se podrá transitar sin gran riesgo, y se irán formando gavillas de ladrones que mañana engrosarán las de Pincheira. Dígnese US. hacer presente a S. E., el señor Director, estos males, para que se sirva determinar lo más conveniente a la seguridad pública" (Letelier, 1901b: 152)32.

El Comandante General de Armas, Luis de la Cruz, apoyando el planteamiento precedente, le pidió al Gobierno que faculte a los militares para que, después de un sumario breve, dichos bandidos "sean fusilados y colgadas partes de sus cuerpos por los caminos que han talado" (Letelier, 1901b: 153).33

Ana María Contador da cuenta de la inutilidad de la acción judicial para enfrentar este fenómeno: "La ineficaz acción del sistema judicial para frenar el bandidaje era una consecuencia de la inoperancia del nuevo aparato estatal y desorganización social imperante" (1998: 74). Esta misma autora cita un documento del Juzgado de Letras de Cauquenes que, el 25 de noviembre de 1827, señalaba: "Una prisión los pone de peor condición, porque en las cárceles aprenden mayores vicios y adquieren relaciones con los asesinos y ladrones, que allí existen de varias provincias". ${ }^{34}$

Esta comunicación es de fecha 4 de abril de 1825.

Esta petición es de fecha 11 de abril de 1825.

Fondo Ministerio del Interior, volumen 42, foja 234 (Archivo Nacional Histórico). 
Volviendo al reclamo por el no pago de los sueldos a la tropa, el Congreso no tomó ninguna resolución definitiva, sino que se limitó a pedir un informe al Ministro de Hacienda sobre las cantidades efectivamente adeudadas. El 18 de abril, el Ministro José Ignacio de Eyzaguirre entregó un cuadro detallado de estas cifras, cuyo total sumaba 94.734 pesos (Letelier, 1901b: 162).

En dicho contacto, Barros Arana da cuenta que el diputado Carlos Rodríguez "declaró con una gran vehemencia, que las tropas no tenían derecho para exigir que sus sueldos fueran pagados cuando el erario público no podía cubrir los de los demás empleados, que la Nación no necesitaba de tantos soldados, y que si éstos se mostraban descontentos podían irse a trabajar a los campos, cuyas faenas debían ocupación a muchos brazos" (2005a: 326).

A través de un oficio del día 8 de mayo (Letelier, 1901b: 244), Rodríguez confirmó este planteamiento, lanzando sus dardos en contra del coronel Beauchef, a quien el día anterior había acusado de emitir palabras ofensivas en contra del Congreso en el marco de un banquete (Letelier, 1901b: 239). La justificación de Rodríguez apuntaba a que la demanda por el pago de los sueldos a la tropa, tenía el carácter de sedición, de la que Beauchef, comandante del batallón № 8, se hacía cómplice:

"El coronel Beauchef se produce con descaro contra el pueblo y su representación, del modo más insolente. Hace pocos días que en una concurrencia insultó a un señor diputado, sin otro principio que por su carácter de tal, y, porque le reprendió dignamente el tono procaz con que se profería contra la más alta corporación de los chilenos. De ordinario trata de degradar y deprimir el crédito y espíritu nacional del país, cuando a él solamente debe el ser conocido en el mundo" (Letelier, 1901b: 244).

Las palabras de Rodríguez en contra de la demanda salarial de las tropas causaron un tremendo impacto en la oficialidad. Durante los primeros días de mayo se emitieron diversas representaciones que rechazaron de la manera más tajante el planteamiento del parlamentario. Al igual que los casos referidos más arriba, estas comunicaciones se hicieron por conducto regular y cuidando expresamente de conservar intacto el principio de supremacía civil.

Al enviar dichas representaciones al Director Supremo, por conducto del Ministro de Guerra, Luis de la Cruz lamentaba el haber tenido que llegarse a esta situación: "No puedo menos de hacer presente el dolor que me oprime el ánimo al ver que la oficialidad del Ejército se halle generalmente ofendida, y que seguramente se hayan combinado para representar por las consecuencias, que son siempre consiguientes al hacer común una ofensa y 
representarla en comunidad" (Letelier, 1901b: 241). Y justificaba su decisión de transmitir el sentir de la oficialidad en el carácter unánime del rechazo a las palabras del diputado Rodríguez:

"Si uno o dos cuerpos sólo hubiesen dado este paso, desde luego habría evitado darle curso, procurando amainar los ánimos exaltados; pero, habiéndose perdido el equilibrio por haberlo hecho, puede decirse todos, la prudencia dicta satisfacer a los interesados dando el curso que piden sus instancias. Por otra parte, V. E. sabe las escaseces en que los cuerpos se hallan, que no hay motivos más poderosos para el aburrimiento que la miseria, y en esta triste situación, verse ofendidos en la Representación Nacional, cuando de ella debían esperar la recompensa de los sacrificios que han hecho en la guerra por la libertad de la Patria, se han visto precisados del dolor y sentimiento a manifestarlo; pues no hay duda que el que padece le es de consuelo el quejarse" (Letelier, 1901b: 241).

Como se observa, el Comandante General de Armas no sólo destacaba el carácter unánime de las representaciones, sino que incluso manifestaba estar de acuerdo con el contenido de las mismas. Pero ¿qué respondió la oficialidad de Santiago frente a las expresiones del diputado Rodríguez? Justo Quinteros, Manuel F. Gutiérrez y Juan Sobaton -oficiales del batallón $N^{\circ} 7$, comandado por el coronel José Rondizzoni-, señalaron el 5 de mayo lo siguiente:

"Los señores oficiales de este batallón, con el debido respeto a US., exponemos: que, a pesar de la debida subordinación que siempre ha sido manifiesta y que jamás nos separamos de ella, hoy día nos es indispensable hacer presente a US. lo siguiente: hasta ahora se han agotado todos los recursos posibles para mantener la moral del soldado. Pero, señor, desde el día $1^{\circ}$ de enero hasta la fecha, no ha sido ajustada la tropa; el crédito de US., no ignoramos que se halla empeñado para dar que comer muchas veces al batallón, vestirlos y calzarlos; nosotros sin nuestros sueldos, perecemos; se nos había dado el consuelo que se iba a ajustar y pagar el Ejército; pero, cuál fue nuestra sorpresa cuando algunos de nosotros hemos oído el discurso de un representante de la Nación, llamado don Carlos Rodríguez, en la sala del soberano Congreso, decir cuando se reclamó se atendiese a los militares, contestar que no se hablase más de ellos, y que fueran a trabajar de peones a las chacras; que allí era donde hacían más falta. Esta será la recompensa que nos espera después de haber vertido nuestra sangre para liberar a Chile, nuestra amada Patria; no digo para ganar un sueldo, ya arriba expresado, pero no poder llegar a más el odio al benemérito" (Letelier, 1901b: 241-242). 
Los oficiales Gutiérrez ${ }^{35}$, Julián Adele, José Videla y José Antonio Novoa -a nombre del regimiento de Cazadores a caballo, comandado por el coronel Benjamín Viel-, se expresaron el mismo día en términos semejantes, aunque sin hacer referencia directa al diputado Rodríguez:

"Los oficiales que suscriben, a nombre de los de sus respectivas clases, ante US. tienen el honor de exponer que se encuentran rodeados de la más espantosa miseria, a causa de no ser cubiertos de sus sueldos después de algunos meses; ésta les obliga a manifestar a US. enérgicamente su deplorable situación, a fin de que se digne elevar este conocimiento al supremo Gobierno, quien, convencido de nuestra resignación, no dudamos tratará de alejar la desgraciada suerte que nos agobia. Ya, señor, no es posible continuaren en un estado tan lamentable; y si hasta ahora hemos guardado un profundo silencio, oprimidos con el peso de esta tan melancólica situación, era porque nos lisonjeábamos con que los padres de la Patria reunidos en augusto Congreso, mirarían algún día a los defensores de ella con aquella consideración a que sus sacrificios les ha hecho acreedores; mas, cuando han visto que del seno mismo de la Representación Nacional, en premio de tantas fatigas, y después de haberse presentado por el Ministro de la Guerra el horroroso cuadro que ofrece la benemérita clase armada, se ha opinado, en lugar de poner remedio a sus males, que aquella se reduzca a la vil, degradante de peones gañanes para lograr su sustento, han quedado sorprendidos, llenándose al mismo tiempo de indignación, que el honor de su profesión tan altamente ofendida les sugiere; y que, por los peligros que han arrostrado por la independencia de su país, han merecido la más afrentosa recompensa" (Letelier, 1991b: 242). ${ }^{36}$

Por su parte, los oficiales Ildefonso Rodríguez, Manuel Vicente Sayago y Juan Acevedo -miembros del batallón № 8, comandado por Jorge Beauchef-, llegaron a hablar de ultraje al honor de ejército por parte del Congreso, agregando:

"[...] que, habiendo soportado con vigor y entusiasmo los asiduos trabajos que han sido inseparables de la guerra que, por la libertad, hemos sostenido, y habiendo puesto en prueba que nuestro celo y ardor patriótico en el largo tiempo que hemos servido de apoyo a la Independencia, no esperábamos que nuestros desvelos y fatigas fueran recompensados con el abatimiento a que nos vemos tan próximos, ni menos con arrojarnos al campo en clase de peones para buscar la comida misma que nuestras virtudes han proporcionado a algunos egoístas que lo desean y declaran públicamente" (Letelier, 1901b: 242). 
Y sobre el asunto concreto que motivó este conjunto de representaciones, señalaron:

“En esta virtud, el cuerpo pide a US. que reclame, por cuantos medios sean compatibles con el decoro militar, la reposición de nuestro honor y crédito; y que, habiéndose producido un miembro de la Representación Nacional diciendo: Que si el ejército no tiene que comer salga a las chácaras, que hay en ellas bastante necesidad de peones, suplicamos al soberano Congreso que reprima al diputado que se propase; la Representación Nacional, tan respetable en sí misma, guarde las consideraciones y respetos al ejército: pues no pende el edificio político más que del equilibrio que mutuamente conservan las corporaciones, y ya que el ejército respeta, es justo que se le corresponda con una santa reciprocidad" (Letelier, 1901b: 242).

\section{Consideraciones Finales}

Al concluir este trabajo, nos parece importante plantear seis consideraciones destinadas a explicar lo anteriormente tratado. Estas consideraciones surgen desde los hechos narrados, considerando que se trata de una época aún poco estudiada, en particular en torno a la cuestión del militarismo.

La primera consideración es que en los motines, a diferencia de los alzamientos o insubordinaciones directamente políticas, suelen adquirir un mayor protagonismo los soldados (algunas veces) en contra de los oficiales. Es lo que Finer llama interés sectorial de clase (1969: 57-62). Así lo vimos en los casos de Los Guindos de enero de 1825 y de Talca de julio de 1827.

Gabriel Salazar subraya la desconfianza de los soldados frente a los oficiales al señalar que los primeros se sentían engañados por los segundos (2000: 247). Sin embargo, aunque esto sea cierto -como debe haberlo sido en los reiterados casos de tener los oficiales que "justificar" los constantes incumplimientos del Gobierno-, puede también sostenerse que la misma situación se daba con relación a los oficiales frente a las elites civiles. Por lo demás -como se vio en las representaciones militares de 1825-, los oficiales actuaron, en no pocas ocasiones, a nombre de los soldados, amén que el no pago de sueldos no era un asunto exclusivo de aquellos, sino que se ampliaba también a los grados superiores. ${ }^{37}$ De esta manera, el interés sectorial de clase se entremezcla con el corporativo.

37 Así, por ejemplo, lo confirma el detallado informe del Ministro de Hacienda, José Ignacio de Eyzaguirre, de fecha 18 de abril de 1825 (Letelier, 1901b: 162). Aunque, para determinar en qué medida, habría que hacer 
En todo caso, un aspecto en que sí resulta notoria la desigualdad entre oficiales y soldados es que, con respecto a los primeros, las elites civiles solían aprobar amnistías o indultos, como puede verse en la sublevación de Chiloé de 1826 y en los alzamientos con tinte federalista de 1827 y $1828 .{ }^{38}$ En cambio, la insubordinación de soldados frente a oficiales, siendo una excepción el caso de Santiago de octubre de 1826, generalmente implicaba que los primeros fueran "pasados por las armas".

Una segunda consideración dice relación con la lucha de los cuerpos militares contra bandas de delincuentes organizados, como la de los hermanos Pincheira. Y si bien este asunto se escapa directamente de las demandas relativas al pago de sueldos -materia esencial de este artículo-, formaba parte del contexto de malestar de oficiales y soldados, que afectaban su moral profesional. Además, resulta interesante considerarlo por dos motivos. Ante todo, porque daba cuenta de que, en buena medida, el ejército del período estaba abocado a tareas de orden público.

Recordemos que el hecho de que las fuerzas armadas se encuentren preferentemente dedicadas a funciones de policía, se constituye en un factor potencial de intervencionismo militar. En palabras de Lorenzo Cotino, la participación de los militares en estas tareas "genera en ocasiones dinámicas paternalistas, contrarias a la separación de la vida política y a la debida percepción militar en una sociedad democrática" (2007: 37).

Además, porque es de suponer que la ejecución de esta misión, en conjunto con el no pago de sueldos, disminuía la moral de los soldados. De esta disminución, y de la sensación de no obtener el merecido reconocimiento de parte de las elites civiles, dan cuenta las representaciones castrenses en respuesta a las palabras del diputado Carlos Rodríguez. Por ejemplo, los oficiales del regimiento de Cazadores a caballo se refieren a sí mismos, incluyendo a los soldados, como defensores de la Patria, sin haber recibido el debido "premio de tantas fatigas" (Letelier, 1901b: 242).

Como tercera consideración, ¿por qué hemos dicho que estas comunicaciones se hicieron por conducto regular y expresando su respaldo al principio de subordinación castrense? Porque transitaron desde la oficialidad a los comandantes de los cuerpos y, desde ellos, al Comandante General de Armas, quien, a su vez, hizo lo propio con el Gobierno. No hay que olvidar

un estudio estadístico referido a los años de nuestro período, lo que se escapa a la metodología cualitativa de este trabajo.

38 Una excepción a esta regla se dio en la llamada "revolución de Sánchez" de 1825, en que los cabecillas fueron exiliados al Perú, pasando a engrosar el grupo de partidarios del prócer que, junto a él, propiciaron la acción de Chiloé del año siguiente. 
que el conducto regular es la forma en que se expresa el carácter jerárquico de las fuerzas armadas (Silva Bascuñán, 1997: 122).

Asimismo, todas ellas contaron con el apoyo de sus comandantes, quienes se pronunciaron de acuerdo con sus oficiales. Por ejemplo, Jorge Beauchef señaló que las palabras del diputado Rodríguez constituían un atentado al honor y la moral de los militares, amén de ser una expresión de falta de agradecimiento por los servicios prestados por ellos (Letelier, 1901b: 242).

Como cuarta consideración, y más allá del respeto al conducto regular, las representaciones referidas dan cuenta de un respaldo formal al principio de supremacía civil. Así se aprecia, por ejemplo, en el documento del batallón N $N^{\circ}$ 7, cuando se señala que "a pesar de la debida subordinación que siempre ha sido manifiesta y que jamás nos separamos de ella, hoy día nos es indispensable hacer presente a US. lo siguiente [...]" (Letelier, 1901b: 241). En general, tanto los comandantes como los oficiales subrayaron que las representaciones se hacían como un último recurso frente a la situación que vivían y, en particular, ante las graves ofensas del diputado Rodríguez.

Lo anterior revela lo mismo que se aprecia en las normas constitucionales de 1823 y $1828^{39}$ : la subordinación como un ideal tanto de civiles como de militares, pero contradicho por la imposibilidad práctica de lograrse plenamente. Desde nuestro punto de vista, en buena medida porque las atribuciones sobre los cuerpos militares estaban desperdigadas en los poderes ejecutivo y legislativo, haciendo que sus miembros pasen a formar parte de la vida política activa. Esto es lo que Samuel P. Huntington denomina control civil subjetivo. Lo que se buscó -al centrar dicho control en el Congreso- fue atraer a los militares al juego político, asociándolos con los distintos bandos y grupos que en él actuaban. Esta será una importante lección que, pasándose al otro extremo (de una subordinación excesiva), recogerá la Carta de $1833 .{ }^{40}$

Como quinta consideración, no deja de llamar la atención -tomando en cuenta que la República se encontraba en pleno proceso de construcción- el hecho de que las representaciones de 1825, a diferencia de los alzamientos y motines, dan cuenta de un alto grado de corporativismo en los cuerpos militares de la capital. Y esto no sólo por el carácter unánime de tales comunicaciones, sino por la circunstancia de señalarse abierta-

39 Para la regulación constitucional de las fuerzas armadas en el período 1823-1830, ver nuestros trabajos sobre la Carta de 1823 y 1828 (ambos de 2015).

40 Aunque con un cierto contrapeso, por ejemplo, a través de las leyes periódicas de orden militar, como la que debía autorizar la fuerza de mar y tierra. 
mente. Por ejemplo, al hablar de la "benemérita clase armada" (Letelier, 1901b: 242) y que el respeto entre las elites civiles (que actuaban en el Congreso) y las militares (que hablaban en ese momento) se sustente en el "equilibrio que mutuamente conservan las corporaciones, y ya que el Ejército respeta, es justo que se le corresponda con una santa reciprocidad" (Letelier, 1901b: 242). ${ }^{41}$

Huntington señala que uno de los elementos fundamentales del carácter profesional de las fuerzas armadas es su corporativismo. "Los imperativos funcionales de seguridad dan origen a complejas instituciones vocacionales que moldean el cuerpo de oficiales hasta convertirlo en una unidad social autónoma" (1985: 27). Al mismo tiempo, siguiendo a Hermann Oehling, esta característica se torna en una ventaja para intervenir políticamente, ventaja que procede de la propia organización militar. "Los cuerpos militares ostentan un entendimiento colectivo, una unidad de acción y un sistema de coordinación superiores al de la sociedad civil" (1977: 226).

Sin embargo, resulta llamativo que el corporativismo militar se haya tornado patente en 1825, es decir, en una época de temprana organización republicana. Una explicación de esto puede buscarse en la historia multisecular de los cuerpos militares organizados en Chile ${ }^{42}$. Pero ¿hasta qué punto existía conciencia en torno a esta historia? El tema amerita un estudio específico, que excede los límites de este trabajo, pero que resultaría interesante de hacer en un futuro.

Como sexta y última consideración, los militares de la época tenían plena conciencia del papel protagónico que estaban cumpliendo en la construcción de la República. No sólo por haber actuado en los campos de batalla, que lograron la Independencia, sino también por la necesidad imperiosa de ser reconocidos y valorados. La molestia de los cuerpos de Santiago frente a las expresiones ofensivas del diputado Rodríguez constituye un ejemplo concreto de un sentimiento general de desconfianza hacia las elites civiles. Siendo ésta la contracara de la desconfianza de las elites civiles hacia los militares, que se aprecia en la regulación constitucional de las fuerzas armadas ${ }^{43}$.

$41 \quad$ El destacado es nuestro.

42 Para la época de dominación española, ver Roberto Oñat y Carlos Roa (1952).

43 Así buscamos demostrarlo en nuestro trabajo sobre la Carta de 1823, referido ut supra. En concreto, este documento fue una extensión de la desconfianza general del liberalismo revolucionario hacia las fuerzas armadas. Por ejemplo, la Declaración de los Derechos del pueblo de Virginia del 23 de junio de 1776 dispuso "que deberían evitarse, en tiempos de paz, como peligrosos para la libertad, los ejércitos permanentes; y que, en todo caso, las fuerzas armadas estarán estrictamente subordinadas al poder civil y bajo su mandato" (Peces-Barba, 1987: 101-105). 
Esta situación revela que los motivos de intervención -aunque, en este caso, no directamente orientados a derrocar gobiernos- se entremezclan entre sí. Los motivos sectoriales tenían también un trasfondo de carácter nacional, aunque sea como excusa. Esto demuestra el carácter aún inestable del país: una República en formación que, por lo mismo, no tenía todavía resueltos aspectos fundamentales de su institucionalidad, siendo uno de ellos el referido a la diferenciación funcional entre civiles y militares.

En términos generales, todo lo anterior da cuenta de lo mucho que todavía falta por estudiar el militarismo de los años de formación de la República en Chile. Un primer paso historiográfico sería reconocer el fenómeno no sólo como existente, sino también como relevante. Este artículo -que espera ser continuado con otros estudios sobre insubordinaciones directamente políticas- se inserta en la línea de este propósito.

\section{Referencias Bibliográficas}

\section{Fuentes Primarias}

\section{a) Documentales}

Fondo Intendencia de Concepción, volúmenes 62 y 86, Archivo Nacional Histórico. Fondo Ministerio de Guerra, volumen 146, Archivo Nacional Histórico.

Fondo Ministerio del Interior, volumen 42, Archivo Nacional Histórico

\section{b) Impresos}

Fariña Vicuña, C. (2007). Epistolario Diego Portales (1833-1837). Santiago de Chile: Ediciones Universidad Diego Portales.

Feliú Cruz, G. (1964). Memorias militares para servir a la historia de la Independencia de Chile del Coronel Jorge Beauchef 1817-1829 y Epistolario 1815-1840. Santiago de Chile: Editorial Andrés Bello.

Peces-Barba, Gregorio (1987). Derecho positivo de los derechos humanos. Madrid: Editorial Debate.

\section{c) Prensa}

El Verdadero Liberal, Santiago, 31 de julio de 1827.

La Aurora, Santiago, 8 de agosto de 1827. 


\section{Fuentes Secundarias}

\section{Publicaciones oficiales}

Benavente, D. (2010). "Memoria que el Ministro de Estado en el Departamento de Hacienda presenta al Senado de la República de Chile", en Opúsculo sobre la hacienda pública en Chile. Santiago de Chile: Biblioteca Fundamentos de la construcción de Chile - Pontificia Universidad Católica de Chile - Biblioteca Nacional (1ª edición, 1824).

Lara, A. (1923). Ordenanza General del Ejército. Santiago de Chile: Imprenta del Ministerio de Guerra.

Letelier, V. (1901a). Sesiones de los Cuerpos Legislativos. Santiago de Chile: Imprenta Cervantes, Tomo $X^{44}$.

Letelier, V. (1901b). Sesiones de los Cuerpos Legislativos. Santiago de Chile: Imprenta Cervantes, Tomo XI.

Letelier, V. (1901c). Sesiones de los Cuerpos Legislativos. Santiago de Chile: Imprenta Cervantes, Tomo XIII.

Letelier, V. (1901d). Sesiones de los Cuerpos Legislativos. Santiago de Chile: Imprenta Cervantes, Tomos XV.

Varas, J. (1870). Recopilación de Leyes y Decretos Supremos concernientes al Ejército. Santiago de Chile: Imprenta Nacional, Tomo I.

\section{a) Artículos}

Barry, D. y Vergara, P. (2013). "De revolucionarios a libertadores. Los oficiales europeos y norteamericanos en el Ejército de Chile. 1817-1830", en Anuario de la Academia de Historia Militar, № 27, pp. 87-131.

Pasquino, G. (2007). "Militarismo", en Norberto Bobbio, Nicola Matteucci y Gianfranco Pasquino (directores), Diccionario de Política. Madrid: Alianza Editorial, pp. 962-970.

Verbal, V. (2012). "El motín de Talca del 21 de julio de 1827. Contexto, acontecimiento y significado", en Anuario de la Academia de Historia Militar, № 26, pp. 9-19.

Verbal, V. (2015). "Las fuerzas armadas en la Constitución de 1828. Una explicación desde las relaciones civiles-militares", en Revista Ensayos Militares, Volumen 1, № 2, pp. 179-191.

44 Los referimos por separado, dado que, tratándose de distintos tomos, los hemos citado con año y letra. 
Verbal, V. (2015). "Las relaciones civiles-militares bajo la Constitución de 1823. Una explicación de sus disposiciones y contexto político", en Derecho Público Iberoamericano, Año IV, № 7, pp. 159-199.

\section{b) Libros}

Alemparte, J. (1963). Carrera y Freire. Fundadores de la República. Santiago de Chile: Editorial Nascimento.

Barros Arana, D. (1852). El General Freire. Santiago de Chile: Imprenta de Julio Belin y Cia.

Barros Arana, D. (2005a). Historia General de Chile. Santiago de Chile: Editorial Universitaria ( $1^{\text {a }}$ edición, 1897), Tomo XIV.

Barros Arana, D. (2005b). Historia General de Chile. Santiago de Chile: Editorial Universitaria (1 ${ }^{\text {a }}$ edición, 1897), Tomo XV.

Berguño, F. (2015). Los soldados de Napoleón en la independencia de Chile (18171830). Santiago de Chile: RIL Editores.

Collier, S. (1977). Ideas y politica de la Independencia chilena. Santiago de Chile: Editorial Andrés Bello (1ª edición, 1967).

Concha y Toro, M. (1862). Chile durante los años de 1824 a 1828. Memoria histórica leída en la sesión solemne de la Universidad de Chile el 12 de octubre de 1862. Santiago de Chile: Imprenta Nacional.

Contador, A. (1988). Los Pincheira. Un caso de bandidaje social. Chile 1817-1832. Santiago de Chile: Bravo y Allende Editores.

Cotino, L. (2007). Supremacía y control civiles de la defensa y las Fuerzas Armadas. Seguimiento y propuestas para América Latina. Barcelona: Fundación CIDOB.

Edwards, A. (1997). La fronda aristocrática en Chile. Santiago de Chile: Editorial Universitaria (1ª edición, 1928).

Edwards, A., y Frei, E. (1949). Historia de los partidos políticos chilenos. Santiago de Chile: Editorial del Pacífico.

Finer, S. (1969). Los militares en la politica mundial. Buenos Aires: Editorial Sudamericana (1ª edición, 1962).

González, E. (1963). Soldados ilustres del Ejército de Chile. Santiago de Chile: Estado Mayor del Ejército.

Heise, J. (1978). Años de formación y aprendizaje políticos 1810-1833. Santiago de Chile: Editorial Andrés Bello.

Huntington, S. (1972). El orden politico en las sociedades en cambio. Buenos Aires: Editorial Paidós. 
Huntington, S. (1985). El soldado y el Estado. Teoría y práctica de las relaciones cívico-militares. Buenos Aires: Grupo Editor Latinoamericano.

Lozoya, I. (2014). Delincuentes, bandoleros y montoneros. Violencia social en el espacio rural chileno (1850-1870). Santiago de Chile: LOM Ediciones.

Oehling, H. (1977). La función política del Ejército. Santiago de Chile: Estado Mayor General del Ejército de Chile (1ª edición, 1966).

Oñat, Roberto, y Roa, C. (1952). Régimen legal del Ejército en el Reino de Chile. Notas para su estudio. Santiago de Chile: Universidad Católica de Chile - Facultad de Ciencias Jurídicas, Políticas y Sociales.

Puigmal, P. (2013). Diccionario de los militares napoleónicos durante la Independencia. Argentina, Chile y Perú. Santiago de Chile: Centro de Investigaciones Diego Barros Arana.

Reyno, M. (1952). Freire. Santiago de Chile: Editorial Zig-Zag.

Salazar, G. (2000). Labradores, peones y proletarios: formación y crisis de la sociedad popular. Santiago de Chile: LOM Ediciones (1ª edición, 1985).

Salazar, G. (2011). Construcción de Estado en Chile (1800-1837). Democracia de los pueblos. Militarismo ciudadano. Golpismo oligárquico. Santiago de Chile: Editorial Sudamericana ( 1 a edición, 2006).

Silva, A. (1997). Tratado de Derecho Constitucional. Santiago de Chile: Editorial Jurídica de Chile, Tomo II.

Varios autores (2000). Economía chilena 1810-1995. Estadísticas históricas, Documento de trabajo № 187. Santiago de Chile: Instituto de Economía, Pontificia Universidad Católica de Chile.

Vergara, S. (1993). Historia social del Ejército de Chile. Santiago de Chile: Departamento Técnico de Investigación - Universidad de Chile, Volumen I.

C) Páginas web

Borja, R., Enciclopedia de la política: www.enciclopediadelapolítica.org 